\title{
The Interplay of Motivation and Demotivation: The Case of EFL Learners Majoring in English
}

\author{
Sultan Al-Sharief \\ Department of English, Umm Al-Qura University, Makkah, Saudi Arabia \\ PO box 13882, Makkah 21955, Saudi Arabia \\ Tel: 9-503-568-100 E-mail: smsharief@uqu.edu.sa
}

Received: 30-07- 2012

Accepted: 13-09- 2012

Published: 01-01- 2013

doi:10.7575/ijalel.v.2n.1p.53

URL: http://dx.doi.org/10.7575/ijalel.v.2n.1p.53

\begin{abstract}
Motivation is widely viewed as a key factor to language learning success. This study investigates motivation among English language majors who are unexpectedly considered by most of their teachers as generally not motivated. Using the model proposed by Deci \& Ryan (1985), the study classifies a sample of English male and female majors ( $\mathrm{n}=365)$ into various levels of motivation. The study further examines the possible demotivational factors that may negatively influence the subjects' motivation. Overall, the findings suggest that the view that the studied sample lack motivation is not accurate. However, the responses to the demotivational factors questionnaire indicate some effective demotivating factors. This effect is particularly statistically significant in relation to the method of teaching. The study concludes by stressing the importance of integrating motivational strategies in any method of EFL classroom teaching even if the learners are expected to be genuinely motivated.
\end{abstract}

Keywords: Motivation, Demotivation, Language learning

\section{Introduction}

There is a widespread agreement among second language acquisition (SLA) researchers on the importance of motivation to language learning success. As categorically stated by Ellis (1994), "SLA research ...views motivation as a key factor in L2 learning" (p. 508). Like success, failure in learning a foreign language may also be attributed to lack of motivation. McDonough (1986) stresses that "motivation of the students is one of the most important factors influencing their success or failure in learning the language" (p. 142). Other factors equal, learners will most likely vary in their language learning performance based on the level of motivation they demonstrate. In general, learners who are more motivated will perform better than those who are not. Backed by these strong views of the importance of motivation to language learning success, teachers often find justification for their students' failure by claiming that they are simply not motivated.

More important than acknowledging that motivation represents a key factor for language learning success is the diagnosis of the motivational status and the reasons behind it to help EFL learners become more motivated. As cleverly put by Oxford and Shearin (1994), "without knowing where the roots of motivation lie, how can teachers water those roots?" (p. 15). This is by no means a straightforward process, partly due to the nature of the motivation phenomenon itself. It is, for example, necessary to adopt a definition of motivation, as agreement on a straightforward, simple definition does not exist. As stressed by Gardner (2006), "motivation is a very complex phenomenon with many facets...Thus, it is not possible to give a simple definition" (p. 242). To capture these "many facets" of motivation, a full definition may be as elaborate as the following:

The dynamically changing cumulative arousal in a person that initiates, directs, coordinates, amplifies, terminates, and evaluates the cognitive and motor processes whereby initial wishes and desires are selected, prioritised, operationalised and (successfully or unsuccessfully) acted out. (Dörnyei \& Ottó, 1998, p. 65)

For the purposes of the present study, a more working definition of motivation may be sufficient. According to Brown (2001), "motivation refers to the intensity of one's impetus to learn" (p. 75). In the foreign language classroom, this is evident in how keen and enthusiastic the learner is; for many language teachers, motivated students are those who participate in the class and continue to be active (Crookes \& Schmidt 1991, p. 480). Further to this definition, full understanding of the phenomenon of motivation requires an identification of its source. In one way or another, most discussions associate motivation to learn a foreign language with two general types of orientation - motives or purposes for learning. Internal or integrative motivation arises from some personal, social, or cultural stimuli and external or instrumental motivation relates to external job or academic motives (Gardner \& Lambert 1959, 1972).

This study investigates the level of motivation, the magnitude of the incentive to learn English, among a group of English language university majors. The specific aim of the study is to verify some teachers' complaints that many 
students are not motivated. To further probe into this problem, the study extends by attempting to figure out the reasons, if any, why students in the sample group may be unmotivated to learn English.

\section{Motivation and demotivation in language learning}

With the tremendous amount of research on motivation, a number of different models have been proposed (Dörnyei \& Ushioda, 2010 reviews many of these models). One useful psychological model that has not been applied in the EFL context until quite recently (see, e.g., Noels, Pelletier, Clément, \& Vallerand, 2003) is Deci and Ryan's (1985) selfdetermination theory (SDT). According to this theory, a person's behavior can be autonomous, initiated from one's self as a personal choice, or controlled, influenced by some interpersonal or external pressure. This is not exactly the same as the well-established broader instrumental/integrative dichotomy referred to by most EFL theories of motivation (cf. Schmidt, Boraie, \& Kassabgy, 1996, p. 14). Following SDT, for example, foreign language learners who do their homework because they perceive its importance for mastering the language are as extrinsically motivated as those who do the same only because they have to follow their teacher's instructions. Though both behaviors are considered extrinsically motivated, they vary in their relative autonomy.

Based on whether actions originate from the self (self-determined) or not, SDT suggests a continuum of motivational types. The most autonomous form of motivation, labelled integrated regulation, is begotten by relatively high interest in the activity. This results in choiceful behaviors that are congruent with the learner's needs and beliefs. Because such behaviors are still done to achieve external outcomes, this form of motivation is considered extrinsic, though it shares many qualities of intrinsic, authentic motivation (Ryan \& Deci, 2000). Less autonomous is identified regulation which is broadly related to how important and useful an activity is perceived. This kind of motivation is what often drives people to aspire to perfect their knowledge and skills. Introjected regulation is relatively controlled and is mainly related to following the rules to avoid feeling guilty or to attain a sense of self-esteem. The farthest kind of motivation on the extrinsic end is external regulation which is the least self-determined and which originates entirely from external sources, such as demands or rewards. It is the kind of motivation traditionally contrasted with genuine, intrinsic motivation.

When there is complete lack of motivation, SDT uses the label amotivation - the state of realizing that there is no point in the activity or that there is incompetency to do it. A related concept is demotivation, which "concerns various negative influences that cancel our existing motivation" (Dörnyei \& Ushioda, 2010, p. 138). The difference is that demotivation is less rooted in the self, and more related to external causes. As soon as demotives become ineffective, people might be motivated again. More attention, especially within EFL instruction, has been given recently to demotivation (Dörnyei \& Ushioda, 2010, p. 144ff). The question most studies of this phenomenon have focused on is what factors contribute to EFL learners' demotivation. For example, using structured interviews with 50 secondary school students indentified as demotivated, some factors reported by Dörnyei (1998, as quoted in Dörnyei \& Ushioda, 2010, pp. 150-5) include: teachers, school facilities, lack of self-confidence, negative attitudes towards the L2 and its community, the compulsory nature of L2 study, attitude of group community, and course books used in class. Falout and Maruyama (2004) construct a questionnaire based on these demotivating factors suggested by Dörnyei concluding that they differ between higher-proficiency and lower-proficiency learners of English. A shorter list of demotivators are extracted through an analysis of Japanese students responses to a questionnaire (Sakai \& Kikuchi, 2009). Compared to teachers, facilities, and lack of intrinsic motivation, the two factors of learning materials and test scores are the most demotivating. Trang and Baldauf Jr. (2007), on the other hand, find that, among four categories related to teachers, the category of teaching methods represents the main source of Vietnamese students' demotivation to learn English.

The two related phenomena of motivation and demotivation have also been thoroughly investigated among Arab learners of English. In a study of motivation among EFL Egyptian adults, Schmidt, Boraie \& Kassabgy (1996) identify, among other things, three motivational dimensions (Affect, Goal Orientation, and Expectancy) which they think account for motivation for their population. Qashoa (2006) examines secondary school students' instrumental and integrative motivation for learning English and reveales that students have a higher degree of instrumentality than integrativeness. The findings indicate that difficulties with English aspects such as vocabulary, structure and spelling were considered to be the most demotivating factors. Al-Tamimi and Shuib (2009) investigate a sample of Yemeni ESP undergraduates' motivation and attitudes towards learning English as a university requirement. Students are unsurprisingly instrumentally motivated, but not very much integratively motivated. Dwaik and Shehadeh (2010) find that the dominant motivation pattern is also extrinsic in nature. Ghaith and Diab (2008) study the effect of some context-specific factors on proficiency development of a group of Saudi college students. An interesting finding of their study is the apparent link between motivation and class participation. They also stress the need for "developmentally appropriate practice based on interesting, motivating, and reader-friendly material" (p. 283). Keblawi (2005) asks Palestinian learners to express in writing what factors demotivate them as they learn English. The analysis shows that two general categories are dominant: contextual demotivating factors, mainly teachers and classmates, and subject demotivating factors, mainly difficulties with English grammar and vocabulary. Finally, Malcolm (2003) surveys how Arab medical students' continue improving their English language proficiency after completing the required English courses in their medical programs. As successful language learners, it is not surprising that almost all of them felt that English is important for their current studies and future career. It is more interesting that $80 \%$ reported some personal reasons, like communication with friends, as making English important to them. Malcolm concludes that this group of medical students has a strong motivation to be good at English. 


\section{Purpose of the study}

The study was motivated by the frequent assertive comments made by most of my colleagues at the English Department about the apparent lack of interest demonstrated by many students. In every meeting, one or more teachers would complain that their students are not willing to learn the language or that they do not show any sign of curiosity about learning the English language. Though the complaint about students' lack of motivation seems to be more widespread among teachers in Saudi schools and universities, it is less expected in such a context where learners are choosing by their own will to major in English. Why would a student who is not motivated to learn English as a foreign language opt to enter an English department? It would therefore be interesting to investigate this issue more formally and try to pinpoint exactly the reasons behind this negative stereotype of English majors. To achieve this goal, two questions were posed: (a) How motivated are students majoring in English? (b) What factors lead to the apparent non-motivation of students majoring in English? Although the study concerns itself with this specific sample of English major students, it is possible to generalize some of the results as will be argued in the results section below.

\section{Method}

As mentioned above, motivation is a complex of constructs; it is difficult to define, and it is even more difficult to observe. Fortunately, the many models of motivation available make this task more accessible. Self-reporting through questionnaires is the method commonly used to investigate motivation (Crookes \& Schmidt, 1991, p. 502). For the purposes of this study, the questionnaire devised by Green (1999) was used to assess the subjects' level of motivation. Green's questionnaire is based on Deci and Ryan's SDT allowing subjects to be classified into four motivation levels: Integrated, Identified, Introjected, and External. Green responded to his focus group's suggestion by adding a fifth level of Avoidance/Rejection to account for instances where learning English is thought to be unimportant, that is lack of motivation. In addition to four initial demographic questions, the questionnaire consisted of eleven statements about language learning each followed by five choices corresponding to the different levels of motivational drives. As an illustration, one item asks the subjects to respond to the statement "When I speak English out of class time, this is mainly because" by selecting one of the following choices: (a) I feel guilty if I do not attempt to use my English [Introjected], (b) my English teachers have advised me to [External], (c) I think that it will lead to improvements in my English [Identified], (d) I enjoy trying out my English out of class time [Integrated], and (e) I never speak English out of class time unless forced to [Avoidance/Rejection]. The questionnaire was translated into Arabic and was reviewed by a translation specialist colleague.

To answer the second question of the study, a questionnaire was designed specifically for this study. Through a review of the literature on demotivation (see above) and through discussions with colleagues and students, five broad demotivating factors were investigated through this questionnaire. These factors were: (Target) Language/Culture, Teachers, Environment, Materials, and Methods. Initially, ten to fifteen statements covering different aspects of each of these subscale factors were presented to a focus group of thirty-two students. These were then analyzed for correlations and five items were then selected to be included in the final draft of the Demotivational Factors Questionnaire (see Appendix). For each statement, participants were asked to express their opinion on a five-point Likert scale ranging from strongly agree to strongly disagree. For most items, strongly agree was coded 5 in the analysis indicating high demotivation (e.g. items 1, 3 and 7); however, some items in each subscale were reverse scored as strongly agree meant low rather than high demotivation effect (e.g. items 2, 4 and 5). Questionnaire reliability was calculated using the Cronbach Alpha formula. The overall reliability coefficient was .72 reflecting an acceptable reliability of instrument (George \& Mallery, 2011).

The subjects of the study were freshman English majors studying at the English Department, Umm Al-Qura University (Makkah, Saudi Arabia). The questionnaire was filled out by a total of 365 participants (after excluding three questionnaires for not being properly filled out). The sample was almost evenly distributed between male and female students: 181 participants were males (49.6\%) and 185 participants were females $(50.4 \%)$. Though not intended, this almost equal distribution of male/female participants helps guard against bias to one sex or the other.

The questionnaire was administered three weeks prior to the end of the first semester. Two groups were taught by me; for the other eight groups, teachers were asked to kindly distribute the questionnaires to their students during class time, collect them, and then return them back to me. Each section of the questionnaire begins with brief instructions and statement of confidentiality; cooperating teachers were encouraged to go through the instructions with the students before they start the completion process. Filling out the two sections did not take more than twenty minutes.

\section{Results}

Following Green (1999), the subjects were categorized into the five types of motivation according to the most commonly selected choices. When equal choices belong to different types of motivation, the case was not included in the categorization. As such, it was possible to classify 289 subjects into one or the other of the different types of motivations assumed by the questionnaire. Figure 1 illustrates the result of this analysis. 


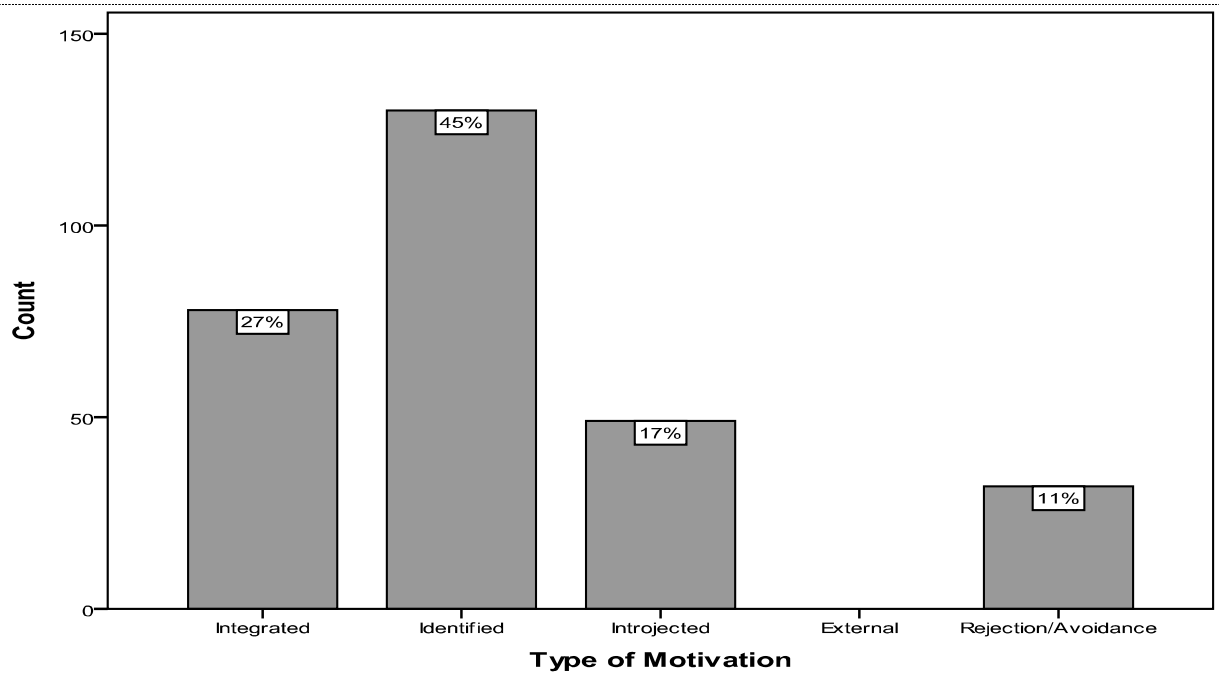

Figure 1. Categorization of subjects according to type of motivation

With two important exceptions, this result is similar to Green's (1999) distribution. The first and most interesting exception is that no subject falls into the External category. The second exception is that a relatively higher percentage of subjects are categorized as Integrated. The percentage of those falling into the Identified category is interestingly similar. Overall, this distribution shows that most of the subjects, about 90 per cent, are indeed motivated to learn English. Only a minority of 11 per cent can be considered as genuinely lackadaisical and unmotivated.

Though the majority of the subjects display high motivation, analyzing the demotives may help explain and probably dispel the stereotypes surrounding students' motivation. The frequencies of responses to the demotivational factors questionnaire are shown in Table 1 below.

Table 1. Frequencies of the demotivational factors questionnaire

\begin{tabular}{ccccccccccc}
\hline & \multicolumn{2}{c}{$\begin{array}{c}\text { Language/ } \\
\text { Culture }\end{array}$} & \multicolumn{2}{c}{ Teachers } & Environment & Materials & \multicolumn{2}{c}{ Methods } \\
\hline $\begin{array}{c}\text { Demotivation } \\
\text { (1=Low; } \\
\text { 5=High) }\end{array}$ & $\mathrm{N}$ & $\%$ & $\mathrm{~N}$ & $\%$ & $\mathrm{~N}$ & $\%$ & $\mathrm{~N}$ & $\%$ & $\mathrm{~N}$ & $\%$ \\
\hline 1 & 814 & 44.6 & 380 & 20.8 & 242 & 13.3 & 131 & 7.2 & 203 & 11.1 \\
2 & 358 & 19.6 & 444 & 24.3 & 359 & 19.7 & 369 & 20.2 & 421 & 23.1 \\
3 & 325 & 17.8 & 482 & 26.4 & 424 & 23.2 & 560 & 30.7 & 646 & 35.4 \\
4 & 161 & 8.8 & 220 & 12.1 & 320 & 17.5 & 386 & 21.2 & 305 & 16.7 \\
5 & 166 & 9.1 & 298 & 16.3 & 478 & 26.2 & 378 & 20.7 & 250 & 13.7 \\
Total & 1824 & 100.0 & 1824 & 100.0 & 1823 & 100.0 & 1824 & 100.0 & 1825 & 100.0 \\
\hline
\end{tabular}

With many choices on the low-end, Language/Culture is the only factor that is clearly not perceived as highly demotivating. Less decisively, Teachers comes next in being less demotivating. The picture is not as clear-cut for the other demotivational factors.

To help investigate any association between the types of motivation and the demotivational factors, a crosstabulation is shown in Table 2.

Table 2. Crosstabulation of motivation types and demotivational factors

\begin{tabular}{|c|c|c|c|c|c|c|c|c|c|c|c|}
\hline \multirow{2}{*}{\multicolumn{2}{|c|}{ Type of Motivation }} & \multicolumn{2}{|c|}{$\begin{array}{c}\text { Language/ } \\
\text { Culture }\end{array}$} & \multicolumn{2}{|c|}{ Teachers } & \multicolumn{2}{|c|}{ Environment } & \multicolumn{2}{|c|}{ Materials } & \multicolumn{2}{|c|}{ Methods } \\
\hline & & Low & High & Low & High & Low & High & Low & High & Low & High \\
\hline \multirow{2}{*}{ Integrated } & $\mathrm{N}$ & 74 & 4 & 31 & 47 & 10 & 68 & 18 & 60 & 23 & 55 \\
\hline & $\%$ & 95 & 5 & 40 & 60 & 13 & 87 & 23 & 77 & 29 & 71 \\
\hline \multirow{2}{*}{ Identified } & $\mathrm{N}$ & 108 & 22 & 64 & 66 & 22 & 108 & 27 & 103 & 50 & 80 \\
\hline & $\%$ & 83 & 17 & 49 & 51 & 17 & 83 & 21 & 79 & 38 & 62 \\
\hline
\end{tabular}




\begin{tabular}{cccccccccccc}
\hline \multirow{2}{*}{ Introjected } & $\mathrm{N}$ & 44 & 5 & 23 & 26 & 15 & 34 & 10 & 39 & 15 & 34 \\
& $\%$ & 90 & 10 & 47 & 53 & 31 & 69 & 20 & 80 & 31 & 69 \\
\hline \multirow{2}{*}{ Rejection/ } & $\mathrm{N}$ & 19 & 13 & 12 & 20 & 5 & 27 & 4 & 28 & 4 & 28 \\
Avoidance & $\%$ & 59 & 41 & 38 & 63 & 16 & 84 & 13 & 88 & 13 & 88 \\
\hline \multirow{2}{*}{ Total } & $\mathrm{N}$ & 245 & 44 & 130 & 159 & 52 & 237 & 59 & 230 & 92 & 197 \\
& $\%$ & 85 & 15 & 45 & 55 & 18 & 82 & 20 & 80 & 32 & 68 \\
\hline
\end{tabular}

One interesting observation is the large number of subjects in the Rejection/Avoidance category (41\%) who view Language/Culture as highly demotivating. This observation becomes more important if we take into account that this effect of Language/Culture is perceived by only 15 per cent of the total number of the categorized subjects. Another important observation is that, contrary to Language/Culture, the totals of Environment and Materials in particular illustrate more demotivating effect ( $82 \%$ and $80 \%$ respectively). To determine which demotivational factors are associated with the different types of motivation in a statistically significant way, a chi square test was sought. The test showed that types of motivation differ by the demotivational factors Language/Culture, $X^{2}(3, N=289)=23.40, p=.00$ and Methods, $X^{2}(3, N=289)=8.375, p=.04$. The test result was not significant for the other three demotivational factors.

\section{Discussion}

The above findings are at first look contradictory. While most of the subjects are motivated, their responses to the demotivation questionnaire indicate high demotivating effect of some factors. This contradiction may reflect the dilemma that has stimulated this study. The sample of the study are English language majors who should be motivated to learn English as evidenced by their choice to willingly join an English department; unexpectedly, they are labelled "unmotivated" by most of their teachers. Motivation is a delicate phenomonenon and it appears that motivational and demotivational factors are in constant competition. Most of the subjects in this study have clear favorable views of the English language and its culture and relatively positive attitude to their English teachers. This seems to compensate for the demotivating effect of the other factors (Environment, Materials, and Methods). Such contradictions are not very uncommon in motivation research. Peacock (1997, p. 152), for example, recommends using authentic materials though his findings were that authentic materials are less interesting than artificial materials. Authentic materials, he stresses are motivating, not because they are interesting, but because they increase levels of concentration and involvement. Many other studies of motivation have attributed variations in results to cultural differences (e.g. Rueda \& Chen, 2005). Students participating in the present study are generally interested in studying English, and they seem to have teachers who try hard to make their language learning experience enjoyable. However, those students are used to the kind of textbook-based materials, teacher-centered classrooms, and traditional teaching methods they experience in their specialized study as English majors. Apparently, this learning context does not help the learners express how authentically motivated they are.

Within Deci and Ryan's SDT, motivation is viewed as dynamic; thus one would expect that over time learners' motivation might be influenced by demotivational factors. In guarding against this, it is essential that teachers adopt some of the advice presented by some researchers of motivation in the instructional settings. For example, Dörnyei (2001) offers thirty five classroom strategies language teachers can use to generate and maintain their students' motivation. Of particular relevance to the current results are the two strategies of presenting tasks properly and promoting learner autonomy. Tasks are very significant in "shaping learners' interest and enthusiasm" (Dörnyei, 2003, p. 14), and autonomy is an important component of the psychology of motivation, especially within SDT. This is why teaching methods are sometimes to blame by less motivated learners (e.g. Trang \& Baldauf Jr., 2007). Incorporating computers in the EFL learning process can also help create a supportive, motivating environment (e.g. Skinner \& Austin, 1999; Ushida, 2005). In addition, materials can be interesting to EFL learners in terms of both format and content (Crookes \& Schmidt, 1991, pp. 491-2).

Like most studies of motivation, the generalizability of the results are normally limited by the scale of the study and the background of the subjects. The attempt made here to seek statistical significance for any association between the types of motivation and the demotivational factors should therefore be put within the specific context of the present study. The findings that there is a significant association between the types of motivation and the two demotivational factors of attitude to language/culture and methods of teaching can probably be generalized to similar learners - Saudi or Arab students - majoring in English. These two factors seem to be at opposite poles. At one pole, the favorable attitude to the English language and its culture intensifies students' motivation and pushes them to deliver their very best in learning the language. At the other pole, common poor pedagogical practices seem to push into the opposite direction of demotivation and non-cooperation in the classroom.

\section{Conclusion}

The findings highlight the importance of classroom motivation and motivational pedagogies. As indicated above, there is an interesting research body that attempts to help teachers motivate language learners. There is, however, "little research [that] has directly investigated how pedagogy interacts with motivation in second language classrooms" (Lightbown \& Spada, 2006, p. 65). This study provides some evidence that the method of teaching, among other things, has an important role to play in motivating learners. As a factor that has unquestionable association with success in 
language learning, positive motivation should therefore be an integral part of any method of classroom language learning. This model that incorporates motivation into pedagogy can subsume not only motivational strategies that teachers can apply to motivate students, but also self-motivating strategies that learners themselves can use to generate and sustain their motivation (Dörnyei, 2003, p. 23). It is such a model that will truly translate the view held for a long time about how "motivation is inseparable from the instructional process and the classroom environment" (Sivan, 1986, p. 209). It is also a model that will encourage learners who are integratively motivated to demonstrate and maintain that motivation in the classroom.

\section{References}

Al-Tamimi, A., \& Shuib, M. (2009). Motivation and attitudes towards learning english: A study of petroleum engineering undergraduates at Hadhramout University of Sciences and Technology. GEMA Online Journal of Language Studies, 9(2), 29-55.

Crookes, G., \& Schmidt, R. W. (1991). Motivation: Reopening the research agenda. Language Learning, 41(4), 469512.

Deci, E. L., \& Ryan, R. M. (1985). Intrinsic motivation and self-determination in human behavior. New York: Plenum Press.

Dörnyei, Z. (1998). Demotivation in foreign language learning. Presented at the TESOL '98 Congress, Seattle, WA, March.

Dörnyei, Z. (2001). Motivational strategies in the language classroom. Cambridge: Cambridge University Press.

Dörnyei, Z. (2003). Attitudes, orientations, and motivations in language learning: Advances in theory, research, and applications. Language Learning, 53(S1), 3-32.

Dörnyei, Z., \& Ottó, I. (1998). Motivation in action: A process model of L2 motivation. Working Papers in Applied Lingaistics (Thames Valley University, London), 4, 43-69.

Dörnyei, Z., \& Ushioda, E. (2010). Teaching and researching motivation (2nd ed.). Harlow, England; New York: Longman/Pearson.

Falout, J., \& Maruyama, M. (2004). A comparative study of proficiency and learner demotivation. The Language Teacher, 28(8), 3-10.

George, D., \& Mallery, P. (2011). IBM SPSS Statistics 19 step by step: A simple guide and reference (12th ed.). New Jersey: Prentice Hall.

Ghaith, G., \& Diab, H. (2008). Determinants of EFL achievement among Arab college-bound learners. Education, Business and Society Contemporary Middle Eastern Issues, 1(4), 278-286.

Green, C. F. (1999). Categorising motivational drives in second language acquisition. Language, Culture and Curriculum, 12(3), 265-279.

Keblawi, F. (2005). Demotivation among Arab learners of English as a foreign language (pp. 49-78). Presented at the Second International Online Conference on Second and Foreign Language Teaching and Research, United States: The Reading Matrix Inc.

Lightbown, P. M., \& Spada, N. (2006). How languages are learned (3rd ed.). Oxford: Oxford University Press.

Malcolm, D. (2003). Investigating successful English learners in Arab medical schools. Supporting independent learning in the 21st century: Proceedings of the inaugural conference of the Independent Learning Association, Melbourne September (pp. 13-14).

Noels, K. A., Pelletier, L. G., Clément, R., \& Vallerand, R. J. (2003). Why are you learning a second language? Motivational orientations and self-determination theory. Language Learning, 53, 33-64.

Peacock, M. (1997). The effect of authentic materials on the motivation of EFL learners. ELT Journal, 51(2), 144 -156.

Qashoa, S. H. H. (2006). Motivation among learners of English in the secondary schools in the eastern coast of UAE (Unpublished MA dissertation). British university in Dubai, Dubai, UAE.

Rueda, R., \& Chen, C. B. (2005). Assessing motivational factors in foreign language learning: Cultural variation in key constructs. Educational Assessment, 10(3), 209-229.

Ryan, R. M., \& Deci, E. L. (2000). Self-determination theory and the facilitation of intrinsic motivation, social development, and well-being. American Psychologist, 55(1), 68-78.

Sakai, H., \& Kikuchi, K. (2009). An analysis of demotivators in the EFL classroom. System, 37(1), 57-69.

Schmidt, R., Boraie, D., \& Kassabgy, O. (1996). Foreign language motivation: Internal structure and external connections. In R. Oxford (Ed.), Language learning motivation: Pathways to the new century. (Technical Report \#11) (pp. 9-70). Honolulu: University of Hawai'i, Second Language Teaching \& Curriculum Center.

Sivan, E. (1986). Motivation in social constructivist theory. Educational Psychologist, 21(3), 209-233.

Skinner, B., \& Austin, R. (1999). Computer conferencing — does it motivate EFL students? ELT Journal, 53(4), 270 279.

Trang, T. T. T., \& Baldauf Jr., R. B. (2007). Demotivation: Understanding resistance to English language learning - the case of Vietnamese students. The Journal of Asia TEFL, 4(1), 79-105.

Ushida, E. (2005). The role of students? Attitudes and motivation in second language learning in online language courses. CALICO Journal, 23(1), 49. 
Appendix: Demotivational Factors Questionnaire

Please check the appropriate box to indicate your opinion about each statement.

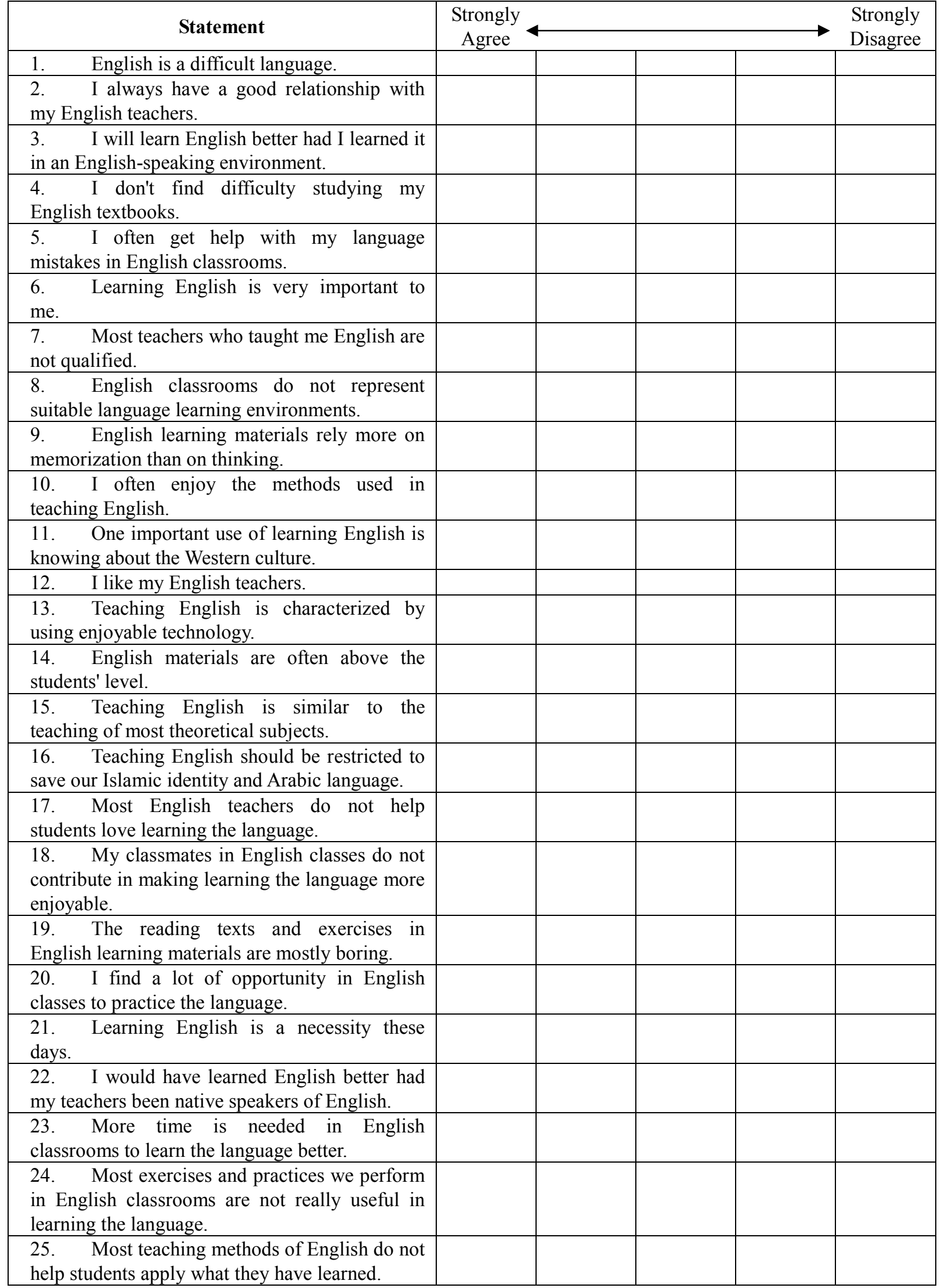

